\title{
MELAWAN ARUS (STRATEGIKOMUNITAS TOLOTANG MEMPERTAHANKAN KEPERCAYAANNYA)
}

\author{
Oleh: Saprilla
}

\begin{abstract}
This study was conducted in Amparita, Sidrap as the center ofTolotang settlement in South Sulawesi. The study aims to describe how Tolotang community maintain their identity from the dominant groups. Data was collected using interview and observation. Interview was conducted with community leader of Tolotang as well as Tolotang community.

This study indicates that Tolotang community has a number strategy in maintaining their identity. These strategies are integrating to Hindu, obscuring people entered into the special place, join to Golkar Party, they also strengthen their community with an exclusive marriage system, they have a strong faith. Then, this community have a good system in maintaining their identity.
\end{abstract}

Key words: Strategy, Tolotang, Identity

\section{A. Pendahuluan}

$\bigcap$ ulisan ini merupakan hasil penelitian yang bertujuan untuk mendeskripsikan bentuk-bentuk tekanan yang dialami oleh komunitas Tolotang dan strategi-strategi yang digunakan oleh komunitas ini dalam mempertahankan eksistensi komunitas dan kepercayaan mereka. Penelitian ini berlangsung selama tiga bulan di Amparita, Kecamatan Tellu LimpoE, Kabupaten Sidrap. Lokasi Amparita ini dipilih karena lokasi ini merupakan tempat pemukiman komunitas Tolotang terbesar di Sulawesi-Selatan.

Teknikpurposive sampling digunakan dalam menetapkan informan yakni komunitas Tolotang sebagai unit analisis. Informan penelitian terdiri Tokoh-Tokoh 


\section{Saprillah}

(ttwa dan uwatta) Tolotang dan masyarakat Tolotang pada umumnya. Data diperoleh melalui wawancara yang ditujukan kepada tokoh-tokoh komunitas Tolotang. Wawancara dimaksudkan untuk mendapatkan gambaran tentang pendapat komunitas Tolotang tentang komunitas dan strategi mereka mempertahankan kepercayaan mereka. Selain wawancara, pengumpulan data juga dilakukan melalui observasi terutama mengenai adat dan upacara-upacara yang dilakukan.

Analisis data dilakukan dengan menelaah seluruh data yang tersedia dari berbagai sumber, yaitu hasil wawancara, catatan lapangan, dokumen-dokumen dan lain-lain. Kemudian mereduksi data, selanjutnya menyusun ke dalam satuansatuan, lalu dikategorisasi. Dan lalu kemudian disusun dalam bentuk tulisan deskriptif.

Pentingnya membicarakan komunitas lokal seperti Tolotang karena komunitas ini tidak banyak mendapatkan posisi penting dalam struktur sosial masyarakat Indonesia. Hal ini karena kuatnya pengaruh ideologi modernisme yang membedakan posisi masyarakat modern dan masyarakat lokal. Masyarakat modern yang hidup di kota dianggap sebagai masyarakat yang cemerlang, beradab, dan hebat. Sementara masyarakat lokal yang hidup di lereng gunung atau di daerah terpencil dianggap sebagai kelompok masyarakat terbelakang, bodoh, dan lemah. Mereka terbelakang karena mereka membiarkan diri mereka tenggelam dalam kekunoan serta menolak raodernitas.

Pengaruh ideologi modernisme sangat jelas terlihat di berbagai kebijakan pemerintah kota di Indonesia, misalnya penggusuran wilayah-wilayah pemukiman kumuh yang dianggap mengganggu keindahan tata kota. Atau pola pembangunan yang lebih diorientasikan pada kepentingan masyarakat kota (lebih tepatnya masyarakat kelas menengah).

Uniknya, logika modernitas teniyata turut pula memengaruhi paradigma kelompok agama besar. Komunitas lokal seperti Tolotang, Kaharingan, Bissu dan lain-lain dalam konfigurasi agama-agama besar dianggap berada di ruang gelap yang bernama kemusyrikan dan kekafiran. Oleh karena itu, mereka harus segera dibersihkan dan diselamatkan melalui proyek salvation atau melalui agamaisasi.

Posisi komunitas penganut kepercayaan lokal menjadi terpojokkan, ketika agama-agama invensionis berhasil mendapatkan legitimasi dari negara melalui UU. No. 1 Tahun 1965. UU ini meresmikan lima agama besar (belakangan 
Saprillah

Menurut kepercayaan mereka, lino paimeng adalah lipu bonga (tempat yang indah) sebagai tempat bagi orang yang mentaati peraturan Dewata dan para uwatta' dan $u w a$ '.

Komunitas ini juga memiliki kitab yang disebut dengan \&ppaungenna Tolotangg, menerangkan tentang asal usul dan inti-inti ajaran kepercayaan Tolotang. Appaungenna Tolotangg merupakan kumpulan pesan-pesan lisan yang tetulis dalam lontara'. Sayangnya kitab ini telah musnah akibat kebakaran besar yang terjadi pada tahun 1970-an.

\section{Sistem Nilai}

Komunitas Tolotang memiliki lima nilai-nilai utama yang menjadi pedoman komunitas ini menjalankan kehidupannya, yaitu:

a. Tettong; secara literal artinya berdiri. Ini merupakan simbol dari konsistensi dan keteguhan hati untuk terus mentaati Dewata Seuwag, meski mengalami berbagai tekanan dan penderitaan.

b. Lempu, secara literal berarti lurus. Ini merupakan simbol dari kejujuran. Kejujuran dalam komunitas Tolotang berarti kejujuran kepada Dewata Seuwag kepada sesama manusia, sesama ciptaan Tuhan dan jujur kepada diri sendiri. Komunitas Tolotang mengenal empat macaw lempu, yaitu : mabbgrg dampeng (memaafkan orang yang salah), dg 'na mabuaja lao riwaramparanna taug (tidak rakus terhadap harta milik orang lain), nalebbirengi padanna rupa tau nennia watangkalg-na (lebih mendahulukan kepentingan komunal atau sosial dibanding dirinya) dan mappalettu paseng (menyampaikan amanah).

c. Tongeng, berarti benar. Kebenaran adalah sesuatu yang dijunjung tinggi dalam komunitas Tolotang.

d. Temmangngingngi; artinya tak pernah jenuh. Nilai temmangingi merupakan ekspresi dari ungkapan masyarakat Bugis pada umumnya : rgsopa temmangingi na malomo nalgtgi pammasg Dgwata (hanya usaha yang tidak kenal lelah, yang mudah mendapatkan restu Dgwata). Dalam komunitas nilai temmangingi sebagai basis untuk terus menerus melakukan perjuangan dalam mempertahankan eksistensinya. Nilai temmangingi ini menjadi inspirasi komunitas ini.

e. Temmappasilaingeng berarti tidak membeda-bedakan. Nilai ini menjadi nilai dasar dalam membangun hubungan sosial yang berbeda-beda. Bagi 
komunitas Tolotang, orang lain bukanlah musuh yang harus diperangi, tetapi kawan. Komunitas Tolotang memiliki sikap yang toleran dan mau membantu siapa saja, tanpa memperdulikan jenis kelamin dan agama.

\section{Sistem Kcpemimpinan/Politik}

Lembaga kepemimpinan Tolotang terdiri atas dua tingkatan, yaitu tingkatan $u w a$ 'ta (selaku pimpinan tertinggi) dan para $u w a$ ' (sebagai pelapis). Lembaga uwa 'ta terdiri atas tiga orang, seorang uwa 'ta Batoa selaku pucuk pimpinan dan dua orang $u w a$ 'ta pendamping. Uwa'ta memiliki tugas penting sebagai pimpinan komunitas yang bertanggungjwab atas keberlangsungan eksistensi komunitas, merencanakan segala hal yang menyangkut kepentingan komunitas, membawahi hukum dan norma-norma adat Tolotang, merencanakan kegiatan adat, dan menetapkan keputusan.

Di bawah tingkat $u w a$ 'ta, berjejer para $u w a$ ' yang berjumlah tujuh orang. Para $u w a^{\prime}$ ini bertugas untuk membantu $u w a^{\prime}$ dan menjalankan kebijakankebijakan dan petuah $u w a^{\prime}$. Para $u w a^{\prime}$ ini biasa juga disebut sebagai ampi'ampina (para penggembala). Tugas utama mereka adalah melakukan hubungan langsung dengan fnasyarakat, melakukan tugas-tugas praktis seperti menerima tamu, menjadi penghulu dalam acara pengantin dan sebagainya. Seluruh kegiatan para $u w a$ ' harus dilaporkan kepada $u w a$ 'ta.

Syarat-syarat untuk menjadi $u w a$ 'ta atau $u w a^{\prime}$ adalah status dalam adat yang tinggi, yaitu para $u w a$ 'ta atau $u w a^{\prime}$ merupakan keturunan dari para $u w a$ 'ta dan $u w a$ ' terdahulu, berani bertindak, jujur, adil, bijak dan berwibawa dan dipilih melalui keputusan sidang adat. Bila seorang $u w a^{\prime}$ meninggal, maka sebelum jasadnya dikebumikan terlebih dahulu diadakan musyawarah adat, atau para perwakilan $u w a^{\prime}$ untuk memilih siapa kira-kira yang pantas dan memenuhi syarat diatas untuk diangkat menjadi $u w a$ '. Selanjutnya $u w a^{\prime}$ yang dipilih oleh sidang adat akan dilantik dalam sebuah kegiatan yang disebut 'maccera atau pakkuru sumange'.

\section{Tekanan-Tekanan Yang dialami}

Sebagai komunitas lokal, Tolotang telah mengalami berbagai model tekanan yang dilakukan oleh negara dan umat Islam. Tekanan yang dialami oleh Komunitas Tolotang dapat dikategorikan kepada dua pola, yaitu Intimidasi dan stigmatisasi.

\section{Intimidasi}

Komunitas Tolotang telah mengalami proses intimidasi sejak pemerintahan Jepang (bersama dengan tokoh-tokoh Islam) melakukan Iarangan 
Saprillah

menyembahyangi orang Tolotang yang meninggal dan larangan menikahkan mereka secara Islam. Padahal sebelumnya mereka telah terbiasa melakukannya secara Islam. Mereka yang berani untuk memanggil imam untuk menyembahyangi akan mendapatkan hukuman dari pemerintah.

Proses intimidasi berlanjut pada zaman DI/TII. Komunitas Tolotang yang dianggap sebagai kelompok musyrik menjadi salah satu target operasi DI/TII. Untungnya pasukan DI/TII tidak pernah masuk di Amparita sehingga tidak sempat melakukan intimidasi fisik. Tetapi beberapa keluarga Tolotang yang hidup di luar Amparita seperti daerah Otting (Tanrutedong) mengalami peristiwa yang menyedihkan seperti pembunuhan.

Pada masa G/30/S/PKI, tekanan terhadap komunitas Tolotang meningkat. Hal ini karena ada tudingan kalau beberapa orang dari komunitas ini terlibat dalam G/30/S/PKI. Tudingan ini kemudian berlanjut dengan program pengawasan yang ketat terhadap segala kegiatan komunitas Tolotang (termasuk Tolotang Benteng). Larangan untuk mengupacarakan secara Islam yang ditetapkan pada masa pendudukan Jepang dicabut. Pemerintah setempat memberlakukan kembali hukum yang lama yakni urusan kematian dan pernikahan komunitas Tolotang harus diupacarakan secara Islam sebagai salah satu cara untuk mengawasi komunitas ini.

Sebagai kelanjutan upaya memberantas sisa-sisa G30.S/PKI, Panglima Kodam XTV Hasanuddin, Brigjend TNI Solihin GP mengeluarkan SK. No. Kep. 0068/7/1967 tentang pembentukan komando operasi Malilu Sipakaenga. Tugas utama dari korps ini adalah meniadakan segala bentuk kegiatan Tolotang, mengajak kembali kepada agama Islam didasarkan kebenaran pada pancasila dan UUD 1945, meningkatkan dakwah secara sistematis dan terarah dalam meningkatkan taraf kehidupan rakyat penegak falsafah negara RI, dan mengusahakan integrasi secara menyeluruh antara penganut Tolotang dengan masyarakat sekitarnya.

Selain tekanan dari pihak pemerintah dan militer, komunitas Tolotang juga mendapatkan tekanan dari organisasi Islam, baik organisasi politik seperti PSII, maupun organisasi sosial keagamaan seperi MUI, Muhammadiyah, Anshor dan sebagainya.

\section{Stigmatisasi}

Stigmatisasi terhadap komunitas Tolotang terkait dengan sistem kepercayaan mereka yang dianggap animis. Oleh karena itu, mereka seringkali dikait-kaitkan dengan kekafiran, kemusyrikan, dan kebodohan. 
Stigma negatif yang muncul terhadap komunitas Tolotang bersumber pada dua hal: pencitraan komunitas Islam dan pencitraan negara yang mengasumsikan komunitas Tolotang sebagai lahan komunisme. Bagian kedua ini dapat dilihat dari resolusi DPR-GR (Dewan Perwakilan Rakyat Gorong Royong) Kabupaten Sidrap, 5 Oktober 1966 yang salah satu poinnya berbunyi:

Bahwa dengan tetap membiarkan kelompok penganut aliran kepertjajaan Toani Tolotang tersebut sebagai kelompok jang tersendiri dalam lingkungan masjarakat Kabupaten Sidenreng Rappang, meskipun diselimuti dan dinaungi atas nama salah satu agama resmi, baik Hindu Bali dan Budha, baik Kristen maupun Islam, maka hal itu terus menerus mengantjam bagi ketenangan dan ketentraman masjarakat dalam bangsa dan negara karena mereka dengan tjiritjirinja dan sifat-sifatnja yang khas jang diakibatkan oleh adat istiadat jang dipaksakan akan tetap merupakan tanah jang subur bagi pengaruh Parpol sisa2 Gestapu/PKI dan pendukung-pendukung gelapnja (lihat lampiran).

Tuduhan keterlibatan komunitas Tolotang dalam PKI, hanya didasarkan pada 'tjiri-tjiri dan sifatnja yang khas, jang diakibatkan oleh adat istiadatjang dipaksakan'. Dengan berdasarkan pada UU No. 1 tahun 1965 tentang lima agama resmi, Tolotang dianggap sebagai komunitas yang 'tidak beragama' karena tidak termasuk dalam salah satu agama yang diakui oleh negara itu. Oleh karena dianggap tidak beragama maka mereka juga dianggap tidak bertuhan. Ciri-ciri tidak bertuhan inilah kemudian yang dianggap 'merupakan tanah jang subur bagi pengaruh parpol sisa2 Gestapu/PKI dan pendukung-pendukung gelapnja'.

\section{Strategi Mempertahankan Kepercayaan dan Komunitas}

Berikut ini akan dijelaskan model-model resistensi yang dilakukan oleh komunitas Tolotang untuk mempertahankan eksistensi komunitas mereka. Model resistensi mereka berorientasi pada dua hal; resistensi kultural dan resistensi politik (formal).

\section{Menghindari Islam dan Berintegrasi dengan Agama Hindu.}

Seperti yang telah dijelaskan pada bagian sebelumnya, komunitas ini pernah mengalami ancaman 'kepunahan' akibat dari kebijakan negara yang telah menetapkan 'hanya' lima agama resmi atau yang dikenal dengan sebutan panca tunggal. Sebagai komunitas yang dianggap 'tidak memiliki agama', mereka diwajibkan untuk berintegrasi dengan salah satu agama resmi yang ada. Situasi ini menjadi sangat sulit bagi komunitas Tolotang. Satu-satunya agama yang dekat dengan mereka adalah Islam, sementara mereka sama sekali tidak punya 


\section{Saprillah}

keinginan untuk masuk Islam. Hal ini kemudian yang mendorong Tolotang mengutus salah seorang kadernya, yaitu saudara Makkatungeng untuk mengurus 'legalitas' Tolotang ke pusat tahun 1966. Sambil menunggu hasil kerja Makkatungeng, beberapa Tokoh Tolotang membuat pernyataan bergabung sementara dengan Islam, sampai ada keputusan tentang agama apa yang seharusnya mereka peluk.

SK. Direktur Jenderal Bimbingan Masyarakat Beragama Hindu Bali/Budha No.2/1966 tanggal 06 Oktober 1996 menetapkan Tolotang sebagai salah satu aliran dalam agama Hindu dan sekaligus menunjuk Makkatungeng untuk melakukan bimbingan dan penyuluhan terhadap komunitas Tolotang. Meski keputusan ini ditentang oleh pihak Islam, tapi Tolotang dengan senang hati menerimanya. Dengan SK itu kelompok Islam atau penguasa lokal tidak lagi memiliki hak untuk mengintimidasi mereka (dengan alasan. tidak beragama) karena mereka kini telah resmi beragama.

Uniknya, meski telah beragama Hindu namun praktik keberagamaan komunitas Tolotang tetap pada kepercayaan lokalnya. Tidak ada satupun petanda yang memungkinkan kita untuk menemukan jejak agama Hindu pada komunitas Tolotang kecuali pada sederet kata "H-I-N-D-U dalam Kartu Tanda Penduduk. Ritual-ritual yang seperti dikemukakan diatas bukanlah bagian dari ritualitas Hindu, konsep Dgwata Seuwaq juga bukan milik agama Hindu, sebutan uwa' untuk pimpinan spritual dan politik komunitas Tolotang, jelas bukan bagian dari agama Hindu, pakaian adat sama sekali tidak berhubungan dengan keyakinan Hindu. Secara subtansial, mereka sama sekali bukan Hindu, tetapi tetap Tolotang.

Keuntungan lain yang diperoleh komunitas Tolotang dengan status bagian dari agama Hindu adalah mereka tetap leluasa untuk memperoleh hak sipil mereka. Banyak warga Tolotang yang berhasil menjadi polisi, guru dan pejabat sipil lainnya, bahkan bisa menjadi anggota dewan sebagai dampak dari normalisasi status mereka. Dengan status sebagai 'penganut Hindu', anak-anak Tolotang juga tidak menemui kesulitan (secara administratif) untuk melanjutkan pendidikan anak-anak mereka ke jenjang yang lebih tinggi, seperti universitas dan sekolah tinggi lainnya.

\section{Keyakinan Yang Kuat}

Keyakinan (ateppereng) adalah salah satu cara komunitas Tolotang untuk mempertahankan identitasnya (terutama kepercayaannya). Menurut $u w a^{\prime} \mathrm{La}$ Unga (22 September 2005): "Apa pun yang terjadi, kami yakin Tolotang tetap 
bisa bertahan meski tekanan yang datang sangat kuat". Keyakinan $u w a^{\prime} \mathrm{La}$ Unga ini dapat saja menjadi representasi dari nalar kolektif komunitas ini. Sejarah perjalanan komunitas Tolotang dalam memproduksi dan mempertahankan identitas komunal mereka adalah salah satu fakta betapa kuatnya nilai-nilai keyakinan dalam komunitas ini. Hal inilah kemudian yang memperkuat keyakinan mereka sebagai Tolotang .

Bagi komunitas Tolotang, kepercayaan tentang Dcwata Seuwag, La Pannaungi yang mendapatkan wahyu, I Pabbcrc sebagai orang yang harus dihargai serta kepercayaan-kepercayaan lainnya adalah sebuah kebenaran yang tidak bisa ditawar-tawar. Kepercayaan Tolotang bagi para penganutnya diyakini akan mampu membawa ke jalan kebenaran. Karena itu ketika ada pertanyaan tentang mengapa mereka memilih mempertahankan kepercayaan mereka daripada masuk agama Islam (misalnya), maka dijawab: "narckko madgcgng mui wasselgna galukku, agapi diala leccg lao rigalunna taug" artinya jika hasil dari sawah kami baik, lalu buat apa pindah ke sawah orang (La Unga Setti, 20 Sepetember 2005). Jawaban ini menunjukkan adanya self-confident (kepercayaan diri) yang besar dalam diri $u w a^{\prime}$ La Unga atas apa yang ia yakini. Ini sekaligus menunjukkan betapa orang-orang lokal yang selama ini dipahami sebagai orang pinggiran memiliki kecerdasan-kecerdasan dalam menalar dan mendialektiskan diskurus yang berkembang di sekitar mereka.

\section{Perkawinan sebagai kontrol genetik}

Komunitas Tolotang menganut sistem perkawinan endogamis, yaitu perkawinan antar sepupu. Atau paling tidak, perkawinan antar individu yang tidak berhubungan darah dalam komunitas. Sangat jarang ditemui, perkawinan antar individu dengan out sider. Hal ini terkait dengan perkawinan sebagai salah satu strategi untuk mempertahankan identitas kelompok. Biasanya anak perempuan $u w a^{\prime}$ dikawinkan dengan keturunan $u w a^{\prime}$ pula, sementara anak laki-laki bebas menikah dengan masyarakat Tolotang pada umumnya.

Pernikahan dengan out sider biasanya diperhadapkan dengan pilihan menjadikan "orang luar" sebagai Tolotang atau tidak sama sekali. Orang dalam yang menikah dengan orang luar komunitas dan memilih keluar dari ikatan komunitas dianggap sebagai Tolaing (orang lain). Kata tolaing (bukan kita) merupakan ekspresi dari cara komunitas ini menentukan siapa diri mereka. Kata to laing menunjukkan meskipun sedarah tetapi telah menyeberangi batasbatas tradisi komunitas Tolotang dan karena itu ia adalah orang luar. 
Dengan demikian, perkawinan menjadi alat politik (kultural) komunitas Tolotang untuk tetap mempertahankan identitas mereka. Komunitas ini nampaknya sadar bahwa perkawinan jika tidak dijaga 'medan politik'-nya akan membahayakan eksistensi mereka ke depan secara genetik.-

\section{Memelihara Sistem Penamaan Tradisional}

Komunitas Tolotang merupakan salah satu komunitas lokal yang masih menerapkan sistem penamaan tradisional terhadap generasi mereka. Pergulatan komunitas Tolotang dengan modernitas dan agama Islam dan Hindu tidak membawa perubahan berarti dalam pemberian nama anak. Tolotang tetap menggunakan asumsi lokal dalam pemberian nama anak mereka, sehingga dalam komunitas Tolotang lazim ditemukan seorang perempuan muda belasan tahun, rambut cepak, berdandan ala anak ABG modern, mengendari sepeda motor, tapi bernama I Coppo atau Tenri Gangka. Demikian pemuda-nya, memakai jeans butut, mengendarai sepeda motor Ninja, tapi namanya tetap La Settiang atau La Ware.

Komunitas Tolotang memberi nama anak sebagai bentuk pelestarian sejarah keluarga. Seorang anak diberi nama dengan memakai nama kakek atau neneknya. Misalnya anak $u w a^{\prime}$ La Unga bernama La Settiang Unga. La Settiang Unga merupakan adopsi dari nama ayah La Unga yang juga sebagai kakek dari Settiang yang bernama La Setti. Begitu pula dengan I Gangka (anak kedua dari uwa La Unga) yang diambil dari nama salah seorang nenek buyutnya. Dengan demikian, pemberian nama bermakna sebagai bentuk penghargaan terhadap generasi sebelumnya dan bisajuga berarti pelestarian secara monumental sejarah keluarga. Selain itu, pemberian nama dalam komunitas Tolotang juga menggunakan konsep pemaknaan dengan harapan akan memberi efek pada sang anak. Misalnya Coppo yang berarti 'puncak' diharapkan sang anak berada di atas puncak kesuksesan.

Dengan tetap memakai nama-nama primordial dan lokal, komunitas Tolotang menunjukkan daya resisten yang luar biasa terhadap pengaruh modernitas dan agama. Komunitas Tolotang tidak terperangkap dalam logika "mengikuti pusat", seperti yang terjadi pada kebanyakan masyarakat Bugis lainnya. Komunitas Tolotang cukup berbangga dengan kelokalannya. Penggunaan nama lokal dalam komunitas Tolotang bisajuga dipahami sebagai proses pembalikan logika relasi pusat-lokal. Jika selama ini kita membayangkan, bahwa komunitas yang berada di wilayah marginal merupakan area permainan kuasa yang empuk dari penguasa. Tolotang membalikkan logika itu. mereka adalah pusat dan yang lain (bahkan yang selama ini dianggap pusat) merupakan marginnya. 


\section{Larangan masuk di Tempat Ritual Sipulung}

Komunitas Tolotang memiliki satu momen dan tempat dimana seseorang yang tidak memiliki hubungan darah dengan Tolotang tidak diperkenankan masuk dan mengambil gambar baik melalui kamera foto atau kamera gerak. Situasi dan tempat yang dimaksud adalah kegiatan sipulung dan kompleks pemakaman nenek moyang diantaranya I Pabbcrc. Kompleks makam ini luasnya sekitar satu hektar dan dikelilingi oleh pohon besar yang berusia ratusan tahun karena pohon-pohon ini memang dilarang untuk ditebang. Di hamparan kompleks pekuburan itulah massa Tolotang berkumpul melingkari pemakaman dan melakukan ritual penghargaan terhadap nenek moyang. Pelarangan terhadap orang luar untuk masuk ke dalam wilayah kuburan pada saat Sipulung, dimaksudkan sebagai upaya untuk menghargai mereka yang sedang melakukan ritual sipulung. Sementara pada hari-hari lain, tidak masalah jika orang diluar komunitas Tolotang mau berkunjung.

Bentuk larangan dan lokalisasi para tamu di tempat tertentu merupakan bagian dari politik kultural komunitas Tolotang dalam upaya untuk menjaga 'keaslian' budaya mereka. Uwa' La Unga (23 September 2005) menganggap bahwa rekaman kegiatan dan pengambilan foto pada saat upacara berlangsung akan mengurangi sakralitas kegiatan mereka. Hal ini karena foto mampu merefleksi dan mengimitasi sebuah obyek dan bagi $u w a^{\prime}$ itu akan mereduksi sakralitas dan kerre" (keramat)-nya ritual. Oleh karena itu mereka selalu tegas menolak dari siapapun yang berusaha untuk mendokumentasikan kegiatan ritual sipulung ini. Hal ini terlihat ketika Dinas Infokom (Informasi dan Komunikasi) Pemerintah Kabupaten Sidrap meminta izin kepada Tolotang agar diperkenankan meliput kegiatan sipulung untuk kepentingan dokumentasi Dinas Infokom Kabupaten Sidrap, tetapi demi menjaga sakralitas dan orisinalitas ritual, para $u w a^{\prime}$ menolak permintaan tersebut.

\section{Resistensi Melalui Politik Formal}

Sejak Pemilu tahun 1972 hingga 2004, komunitas Tolotang selalu berhasil mendudukkan wakilnya di DPRD Sidrap. Bahkan uwa Tobotiu sempat menduduki kursi legislatif tingkat I pada tahun 1980-an. Uwa Launga sempat duduk dua periode sejak tahun 1992-2004. Untuk periode 2004-2009, kader Tolotang yang menduduki kursi legislatif tingkat DPRD adalah $u w a^{\prime}$ Bunga Eja. Sejak pemilu 1972 sampai pada pemilu 2004, komunitas Tolotang memperlihatkan loyalitasnya yang tinggi dengan memberi dukungan kepada Golkar.

Keberhasilan Tolotang terlibat dalam dunia politik meski berbekal pendidikan formal yang. tidak terlalu tinggi (tercatat $u w a^{\prime}$ La Unga hanya mengenyam 
pendidikan hinggabangku SMP, begitu pula dengan anggota legislatif yang lain) adalah bentuk kemampuan mereka dalam menegosiasi potensi yang mereka miliki yaitu massa yang banyak. Uwa' La Unga menyatakan, bahwa sejak awal bergabung dengan Golkar, para $u w a^{\prime}$ memang telah meminta komitmen kepada pimpinan Golkar untuk memberi ruang politik bagi komunitas Tolotang.

Lalu apa untungnya Tolotang berpolitik? Uwa" La Unga sebagai salah seorang mantan anggota DPR menyatakan, bahwa kehadiran orang-orang Tolotang di legislatif akan lebih mudah dalam pengawasan kebijakan yang nantinya merugikan komunitas Tolotang. Jadi dengan menempatkan wakil mereka di DPRD tidak saja mengangkat citra orang-orang Tolotang, tetapi juga untuk melindungi komunitasnya dari 'ancaman-ancaman' kebijakan yangmenindas eksistensi mereka.

\section{E. Penutup}

Sebagai komunitas lokal yang terpinggirkan oleh nalar dominan, komunitas Tolotang telah mengalami begitu banyak tekanan-tekanan yang beror ientasi pada pelenyapan eksistensi Tolotang. Negara dan Agama Islam menjadi aktor yang paling sering melakukan proses penyingkiran itu. UU no. 1 tahun 1965 tentang peresmian lima agama (Islam, Kristen, Katolik, Hindu dan Budha) adalah salah satu kebijakan yang membuat Tolotang hampir kehilangan identitas mereka. Selain itu, regulasi-regulasi pemerintah lokal yang mengarah pada penyingkiran komunitas Tolotang. Demikian halnya dengan agama Islam yang direpresentasikan oleh Partai Islam seperti PSI dan organisasi keagamaan seperti Anshor dan Muhammadiyah ikut serta dalam proyek penyingkiran komunitas Tolotang. Asumsi yang digunakan untuk melegitimasi program penyingkiran itu adalah bahwa Tolotang itu musyrik, kafir, tidak bertuhan dan bagian dari PKI.

Oleh karena stigma itulah, komunitas Tolotang menjadi komunitas yang terpinggirkan. Hak-hak mereka terganggu, terutama hak untuk melaksanakan kepercayaan mereka. Selain itu, banyak warga di luar Tolotang menganggap komunitas ini sebagai komunitas kelas dua dan tidak layak untuk berinteraksi dengan mereka.

Namun komunitas Tolotang bukanlah komunitas yang lemah, yang dengan mudahnya terjebak dalam lingkaran stigma dan konstruksi negatif tadi. Mereka adalah komunitas yang cerdas. Mereka mampu mensiasati upaya penyingkiran yang secara sistematis dilakukan oleh negara dengan "berintegrasi" kepada salah satu agama yaitu Hindu. "Integrasi" mereka ke agama Hindu ini memberi ruang bagi mereka untuk 'menyelamatkan diri' dari UU. No 1 tahun 1965 tadi. Dengan demikian, Hindu menjadi tameng mereka terhadap regulasi negara 
dan sekaligus menjadi instrumen adminstratif untuk memperoleh hak-hak sipil seperti hak mendapatkan pengakuan negara melalui KTP, hak untuk mendapatkan pendidikan formal dan hak untuk bekerja di instansi negara. Mereka mensiasati kedatangan orang-orang luar ke acara sipulung dengan melokalisasi para pengunjung di tempat khusus. Bahkan mereka berhasil menggunakan partai Golkar untuk masuk ke parlemen, dan dengan begitu mereka bisa mengawasi semua regulasi yang membahayakan komunitas mereka. Di samping perlawanan keluar, komunitas Tolotang juga memperkuat komunal mereka dengan sistem perkawinan, sistem penamaan dan keyakinan yang kuat.

Kemampuan komunitas ini untuk mempertahankan diri dari berbagai tekanan dan stigmatisasi, menunjukkan bahwa mereka memiliki kecerdasan dan power. Karenanya, teori pemberdayaan sebagai alat untuk melihat posisi komunitas lokal sebaiknya tidak dipakai lagi, dan digantikan pemberian ruang yang sebesar-besarnya.

Berdasarkan hal di atas, penulis menyarankan perlunya negara mengakomodasi kepercayaan-kepercayaan lokal sebagai salah satu kepercayaan yang diakui sebagaimana layaknya agama. Di samping itu, komunitas lokal adalah komunitas yang hidup, bukan pajangan danbukan pulatontonan. Oleh karenanya, regulasi kebudayaan dan pariwisata yang cenderung menjadikan komunitas lokal sebagai lahan untuk mendapatkan devisa sebaiknya direvisi agar tidak terjadi proses dehumanisasi.

\section{DAFTAR BACAAN}

Aschroft, Bill. Gareth Griffith dan Helen Tiffin. 2003. Menelanjangi Kuasa Bahasa, Teori dan Praktik Sastra Poskolonial (terj). Qalam, Yogyakarta.

Barker, Chris. 2004. Cultural Studies, Teori dan Praktik (terj). Kreasi Wacana, Yogyakarta.

Baharuddin. 1992. Towani Tolotang: Tinjauan Sosiologi Agama (Skripsi). Fakultas Ushuluddin, IAIN Alauddin, Makassar.

Baso, Ahmad. 2002. Plesetan Lokalitas: Politik Pribumisasi Islam. Desantara, Jakarta. . 2005. Islam Postkolonial. Mizan, Bandung.

Bennett, T. 1998. Culture: A Reformer's Science. St. Leonard, NSW: Allen and Unwin.

Bhaba, Homi K. 1994. The Location of Culture. Routledge, London and New York.

Daeng, Hans.J. 2005. Manusia, Kebudayaan dan Lingkungan; TinjauanAntropologis. Pustaka Pelajar, Yogyakarta.

Dalle, Muh. Syukri. 1982. Toani Tolotang di Kabupaten Sidenreng Rappang. Skripsi. IAIN Alauddin, Makassar.

De Jong, Chris GF. 1996. Ilalang Arenna Sejarah lending Belanda di antar a Umat Bugis dan Makassar Sulawesi Selatan. Bpk. Gunung Mulia, Jakarta. 
Saprillah

Effendi, Bisri (2002) MelawanLupa: Budaya Lokal Sebagai Perlawanan, Desantara, Jakarta.

Giddens, Anthony. 1984. The Constitution of Society. Polity Press, Cambridge 1991. Modernity and Self Identity.. Polity Press Cambridge. , 2003. Masyarakat Post Tradisional. Ircisod, Yogyakarta.

Hefner, Robert. 2002. Geger Tengger. LKiS, Jogyakarta.

Jenkins, Richard. 2004. Membaca Pikiran Pierre Bourdieu. Kreasi Wacana, Yogyakarta. Koentjaraningrat. 1981. Pengantar IlmuAntropologi. Aksara Baru, Jakarta. - 1987. Sejarah Teori Antropologi I. Universitas Indonesia Press, Jakarta. 1995. Kebudayaan, Mentalitas dan Pembangunan. Gramedia, Jakarta.

Kurniawan. 2001. Semiologi Roland Barthes. Indonesiatera, Magelang.

Malik, Thahir, 2004, Kepemimpinan Uwa Terhadap Motivasi dan Disiplin Kerja Komunitas Tolotang di Kabupaten Sidenreng Rappang. Universitas Hasanuddin, Makassar.

Mardalis. 1990. Metode Penelitian, Suatu Pendekatan Proposal. Bumi Aksara, Jakarta. Moleong, L. J., 2000, Metodologi Penelitian Kualitatif. PT. Remaja Rosalakarya, Bandung.

Morley, David. 1992. Television, Audiences and Cultural Studies. Routledge, London and Newyork.

Mudzhar, Atho. 1985. "Mesjid dan Bakul Keramat". Dalam Mukhlis dan Kathryn Robinson, (ed). Agama dan Realitas Sosial. Lembaga Penerbitan Universitas Hasanuddin, Ujungpandang.

Mukhlis 1987. OrganisasiKepercayaan terhadap Tuhan YangMahaEsaPropinsi Sulawesi Selatan. Departemen Pendidikan dan Kebudayaan. Dirjen Kebudayaan dan Pembinaan Penghayat Kepercayaan Terhadap Tuhan Yang Maha Esa Sulawesi-Selatan.

Pals, Daniel. L. 2001. Seven Theories of Religion. Qalam, Yogyakarta.

Said, Edward. W. 2001. Orientalisme. Pustaka, Bandung.

Saidi, Anas. 2004. MenekukAgama, Membangun Tahta. Desantara, Jakarta.

Sardar, Ziaduddin dan Borin Van Loon. 2001. Cultural Studies For Beginner, Mizan, Jakarta.

Smith, Rita. 1996. Dissociated Identities, Ethnicity, Religion, and Class in Indonesia. University of Michigan Press, USA.

Spivak, Gayatri C. 2003. Membaca Pemikiran Jacques Derrida, Sebuah Pengantar. Arruz, Yogyakarta.

Syamsuddin. HT Drs. 1983/1984. Hasil Penelitian Masyarakat Toani Tolotang dan Patuntung di Sulawesi Selatan (Studi Perbandingan tentang kepercayaan), Proyek Penelitian Keagamaan DEPAG RI, Ujungpandang.

TimBPS.2003.Kecamatan TelluLimpoE dalamAngka. BalaiPusat StatistikSulawesiSelatan, Makassar.

Willis, Paul (1980) Common Culture. Open University Press. Keyness.

Wuthnow, Robert. Cultural Analysis. Routledge. London and Newyork.

Zayd, Nashr Hamid Abu. 2002. Tekstualitas Qur 'an. LKIS, Jogyakarta. 